\title{
RELATO DE UMA EXPERIÊNCIA COM ADOLESCENTES INTERNOS QUE CUMPREM MEDIDAS SOCIOEDUCATIVAS ATRAVÉS DE UM PROJETO DE EXTENSÃO
}

\author{
Ananias Francisco dos Santos ${ }^{1}$ \\ Orcid 0000-0002-3848-2565 \\ RubENS DOS SANTOS ${ }^{2}$ \\ Orcid 0000-0003-4608-6279
}

\begin{abstract}
Resumo: Este artigo objetivou relatar a experiência com adolescentes internos que cumprem medidas socioeducativas através de um projeto de extensão. Para atingir o objetivo proposto, foi realizado um acompanhamento do curso Microempreendedor Individual (MEI), que faz parte do Projeto de Extensão intitulado "A Contabilidade como instrumento de ressocialização dos adolescentes internos do Polo Masculino do Município de Cáceres-MT ao mercado de trabalho e ao convívio social", ministrado no período de agosto a outubro de 2018. Percebeuse, durante e após a conclusão do curso, o entusiasmo dos adolescentes que concluíram o curso com aproveitamento, a possibilidade de abrir o próprio negócio após ganharem a liberdade, além de contribuir com a formação pessoal e profissional permitindo-lhes sonhar com um futuro melhor. A experiência obtida pelos membros e colaboradores, após a conclusão do curso MEI, mostrou a importância de um Projeto de Extensão voltados para esse público, o que possibilitou reflexões pessoais, profissionais e espirituais, após conhecer a realidade em que vivem os adolescentes que cumprem medidas socioeducativas, além da importância do curso no resgate da cidadania perdida e a melhoria da autoestima de cada participante.
\end{abstract}

Palavras-chave: Adolescentes Internos. Projeto de Extensão. Medidas Socioeducativas.

1 Professor do Curso de Ciências Contábeis da Universidade Estadual do Mato Grosso (UNEMAT). ORCID oooo-0002-3848-2565

2 Professor do Curso de Ciências Contábeis da Universidade Estadual do Mato Grosso (UNEMAT) 


\section{REPORT OF AN EXPERIENCE WITH INTERNAL ADOLESCENTS MEETING SOCIO-EDUCATIONAL MEASURES THROUGH AN EXTENSION PROJECT}

Summary: This article aimed to report the experience with internal adolescents who comply with socio - educational measures through an extension project. In order to reach the proposed objective, a follow-up to the Individual Microentrepreneur (MEI) course was carried out, which is part of the Extension Project entitled "Accounting as an instrument for resocialization of the inner adolescents of the Male Polo of the Municipality of CáceresMT to the labor market and to social interaction, "taught in the period from August to October 2018. It was noticed during and after the conclusion of the course, the enthusiasm of adolescents who successfully completed the course, the possibility of opening their own business after gaining freedom, in addition to to contribute to the personal and professional formation allowing them, to dream of a better future. The experience gained by the members and collaborators, after completing the MEI course, showed the importance of an Extension Project aimed at this audience, which made possible personal, professional and spiritual reflections, after knowing the reality in which the adolescents live that comply with measures socio-educational, and the importance of the course in the recovery of lost citizenship and the improvement of the self-esteem of each participant.

Keywords: Internal Adolescents. Extension project. Educational Measures.

\section{RELATO DE UNA EXPERIENCIA CON ADOLESCENTES INTERNOS QUE CUMPLEN MEDIDAS SOCIOEDUCATIVAS A TRAVÉS DE UN PROYECTO DE EXTENSIÓN}

Resumen: Este artículo objetivó relatar la experiencia con adolescentes internos que cumplen medidas socioeducativas a través de un proyecto de extensión. Para alcanzar el objetivo propuesto, se realizó un seguimiento del curso Microemprendedor Individual (MEI), que forma parte del Proyecto de Extensión titulado "La Contabilidad como instrumento de resocialización de los adolescentes internos del Polo Masculino del Municipio de CáceresMT al mercado de trabajo y a la convivencia social ", impartida en el período de agosto a octubre de 2018. Se percibió durante y después de la conclusión del curso, el entusiasmo de los adolescentes que concluyeron el curso con aprovechamiento, la posibilidad de abrir el propio negocio después de ganar la libertad, además de contribuir con la formación personal y profesional permitiendo a los mismos, soñar con un futuro mejor. La experiencia obtenida por los miembros y colaboradores, después de la conclusión del curso MEI, mostró la importancia de un Proyecto de Extensión dirigido a ese público, lo que posibilitó reflexiones personales, profesionales y espirituales, después de conocer la realidad en que viven los adolescentes que cumplen medidas socioeducativas, y la importancia del curso en el rescate de la ciudadanía perdida y la mejora de la autoestima de cada participante.

Palabras clave: Adolescentes Internos. Proyecto de Extensión. Medidas socioeducativas.

Submetido em: 03/01/2019

Aceito em: 25/02/2019 


\section{INTRODUÇÃO}

A Extensão Universitária, sob o princípio constitucional da indissociabilidade entre ensino, pesquisa e extensão, é um processo interdisciplinar, educativo, cultural, científico e político que promove a interação transformadora entre Universidade e outros setores da sociedade. É o processo educativo, cultural e científico, que articula o ensino e a pesquisa de forma indissociável e viabiliza a relação transformadora entre a Universidade e a sociedade (FORPROEX, 2001).

Seu objetivo, de acordo com Nogueira (2005), é o de implementar o processo de democratização do conhecimento obtido no meio acadêmico, estabelecer mecanismos de integração entre os saberes acadêmico e popular, de forma que a produção do conhecimento se efetive no confronto com a realidade, com permanente interação entre teoria e prática.

Por outro lado, sabe-se que os estabelecimentos prisionais têm sido ineficientes em promoverem a ressocialização dos adolescentes que cumprem medidas socioeducativas, o que representa uma discordância com a legislação brasileira, em especial a Constituição Federal e o Estatuto da Criança e do Adolescente (ECA), na medida em que prevê políticas públicas destinadas à reintegração social do adolescente.

Segundo o SINASE (2016), os adolescentes que cumprem medidas socioeducativas em unidades de internação praticaram 27.799 atos infracionais em 2016. Desse total, 47\% (12.960) do total de atos infracionais em 2016 foram classificados como análogo a roubo (acrescido de $1 \%$ de tentativa de roubo), e $22 \%$ (6.254) foram registrados como análogo ao tráfico de drogas. $\mathrm{O}$ ato infracional análogo ao homicídio foi registrado em 10\% (2.730) do total de atos praticados, acrescido de $3 \%$ de tentativa de homicídio.

As principais causas que contribuem para o aumento dos jovens menores de 18 anos em diversos crimes estão relacionadas à pobreza extrema, à violência e à exclusão social. Sabe-se que esses adolescentes são cidadãos brasileiros e têm direitos à educação, independentemente das infrações cometidas, que é garantido por lei e não um privilégio.

Portanto, é obrigação do Estado prestar assistência aos adolescentes que se encontram internados nos Centros Socioeducativos, com o objetivo de prevenir a prática do crime e orientando os mesmos ao retorno do convívio em sociedade. A reinserção destes adolescentes na sociedade e ao mercado de trabalho objetiva humaniza-los, transformando-os as suas personalidades 
juntamente com a assimilação de valores morais necessários para torná-lo apto a viver socialmente.

A Universidade Estadual do Mato Grosso (UNEMAT), representante do Estado no Município de Cáceres-MT, cuja missão é oferecer educação superior pública de excelência, promovendo a produção do conhecimento por meio do ensino, pesquisa e extensão contribuindo para uma sociedade mais humana e democrática, aderiu ao "Pacto Universitário pela Promoção do Respeito à Diversidade, da Cultura e da Paz e dos Direitos Humanos cujo o objetivo é superar a violência, o preconceito e a discriminação por meio de atividades educativas de promoção e defesa dos direitos humanos" do Ministério da Educação e Cultura (MEC).

Como forma efetiva da aderência este pacto, a UNEMAT nos últimos anos, tem desenvolvido projetos de extensão, com objetivos relacionados às áreas temáticas de Comunicação, Cultura, Educação, Meio Ambiente, Saúde, Trabalho, Tecnologia e Produção e Direitos Humanos e Justiça. Um dos projetos de extensão em andamento voltados para a redução da desigualdade social é "A Contabilidade como instrumento de ressocialização dos adolescentes internos do Polo Masculino do Centro Sócio Educativo do Município de Cáceres-MT ao mercado de trabalho e ao convívio social". Este artigo objetivou relatar a experiência com adolescentes internos que cumprem medidas socioeducativas através de um projeto de extensão.

Esta pesquisa se justificou por mostrar, por meio de relatos de experiências vivenciadas na prática, o que a UNEMAT tem oferecido aos adolescentes que cumprem medidas socioeducativas no Município de Cáceres-MT através da extensão, visando proporcionar-lhes o despertamento pelos estudos, o resgate da dignidade, da cidadania perdida e a da autoestima, intervindo, dessa forma, nos fatores que alimentam a reincidência criminal contribuindo, para mudanças nos comportamentos antissociais.

\section{O RELATO DA EXPERIÊNCIA}

\subsection{O PROJETO DE EXTENSÃO}

As ações do projeto se iniciaram em agosto de 2018 pelo coordenador e dois colaboradores do curso de Ciências Contábeis da UNEMAT, Campus 
Universitário Jane Vanini em Cáceres-MT em parceria com o Centro Socioeducativo Polo masculino do Município de Cáceres.

Para sua implementação, realizaram-se reuniões com os representantes da Pró-reitoria de Extensão e Cultura da UNEMAT, do Centro Socioeducativo, além do Coordenador do Projeto. Os objetivos das reuniões visaram conhecer as características peculiares dos adolescentes que se encontravam cumprindo medidas socioeducativas para, a partir daí, traçar metas e estratégias de ensino a ser praticada durante os encontros presenciais.

O Projeto de Extensão cujo título "A Contabilidade como instrumento de ressocialização dos adolescentes internos do Centro Sócio Educativo de Cáceres-MT ao mercado de trabalho e ao convívio em sociedade" tem como público-alvo os adolescentes que estejam submetidos à medida de proteção sob a responsabilidade do Estado.

O objetivo geral do Projeto é ministrar temas contábeis, demandados pelo mercado de trabalho, aos Adolescentes Internos do Centro Regional de Atendimento Socioeducativo Masculino - Polo de Cáceres, preparando-os para serem reintegrados à sociedade.

Para cumprir o objetivo geral, adotaram-se como objetivos específicos:

a. Despertar, na pessoa do adolescente interno, o interesse pelos estudos, em especial pela contabilidade, motivando-os a sua inserção ao mercado de trabalho;

b. Oferecer oportunidade para os adolescentes internos desenvolverem seu senso crítico, para refletir sobre as suas necessidades no desenvolvimento das competências profissionais nas áreas contábeis, levando-os ao seu crescimento pessoal e profissional;

c. Resgatar, por meio do ensino da contabilidade, a dignidade, a cidadania perdida e autoestima do reeducando, possibilitando sua reintegração social com uma melhor qualidade de vida;

d. Motivar os adolescentes internos, por meio de práticas contábeis, a mudar comportamentos antissociais, sentimentos em relação a pessoas do mesmo grupo e relacionamentos com elas;

e. Intervir nos fatores que alimentam a reincidência criminal, proporcionando, aos adolescentes internos, através da contabilidade, meios para a sua autossustentabilidade e da sua família; e 
f. Promover melhora na relação afetiva familiar dos adolescentes internos, combinada com aumento no monitoramento e supervisão por parte da família.

O projeto de extensão está composto por 3 (três) professores da UNEMAT como membos, sendo 2 (dois) doutores e 1 (um) mestre. Tem ainda como colaboradores, 1 (um) professor mestre contratado, dois profissionais técnicos efetivos e ainda, 3(três) graduandos do curso de Ciências Contábeis. Para compor definitivamente a equipe do projeto de extensão, solicitaram-se 2 (dois) bolsistas.

Os cursos com as respectivas cargas horárias que compõem o projeto estão evidenciados no Quadro 1.

Quadro 1-Cursos que compõem o Projeto de Extensão

\begin{tabular}{|c|c|}
\hline CURSOS & CARGA HORÁRIA \\
\hline MICRO EMPREENDEDOR INDIVIDUAL & 30 HORAS \\
\hline EMPREENDEDORISMO & 30 HORAS \\
\hline ÉTICA CONTÁBIL & 30 HORAS \\
\hline IMPOSTO DE RENDA PESSOA FÍSICA & 30 HORAS \\
\hline COMPRAS GOVERNAMENTAIS & 30 HORAS \\
\hline SIMPLES NACIONAL & 30 HORAS \\
\hline FORMAÇÃO DO PREÇO DE VENDA & 30 HORAS \\
\hline FOLHA DE PACAMENTO & 30 HORAS \\
\hline ESCRITURAÇÃO CONTÁBIL E FISCAL & 40 HORAS \\
\hline
\end{tabular}

Fonte: Projeto de EXTENSÃo (2018)

Os critérios das escolhas se basearam na possibilidade de adolescentes, que concluírem com aproveitamento os cursos, desempenharem as atividades de forma independente após ganharem a liberdade, bem como na possibilidade de serem inseridos no mercado de trabalho, conforme a demanda do mercado local. O primeiro curso concluído com aproveitamento foi o de Microempreendedor Individual (MEI), que será abordado no item a seguir.

\subsection{O GURSO MICROEMPREENDEDOR INDIVIDUAL (MEI)}

No Brasil, há muitos desempregados trabalhando por conta própria, ou seja, na informalidade, para sobreviver e manter a família com o mínimo de 
dignidade, trazendo prejuízos aos cofres públicos, principalmente para a Previdência Social.

A Lei Complementar no 123 de 14 de dezembro de 2006, que instituiu o Simples Nacional, foi alterada pela Lei Complementar $n^{\circ} 128$ de 19 de dezembro de 2008, criando uma nova figura conhecida como Microempreendedor Individual, também conhecido como MEI.

Oliveira e Forte (2014) afirmam que a nova figura jurídica do Microempreendedor Individual (MEI) teve o propósito de formalizar milhões de brasileiros que viviam na informalidade, pois não havia legislação voltada para esse público.

Na opinião de Lopes e Campos (2011), a política pública do Microempreendedor Individual é focada em combater a informalidade, criar facilidades para a formalização de trabalhadores que se encontram no setor informal, com a finalidade de conseguir diminuir a informalidade e, como consequência, aumentar o bem-estar social.

Todavia, é importante que aqueles que pretendam se formalizar como MEI que deve prestar atenção nos seguintes pontos:

a. Verificar se recebe algum benefício previdenciário;

b. Procurar a prefeitura para verificar se a atividade pode ser exercida no local desejado;

c. Verificar se as atividades escolhidas podem ser registradas como MEI.

A Lei Complementar no 123/06 define o MEI no parágrafo $1^{\circ}$ do Art. 18-A, da seguinte maneira:

O MEI é o pequeno empresário individual que atende as condições abaixo relacionadas: a) tenha faturamento limitado a R\$ $81.000,00$ por ano; b) que não participe como sócio, administrador ou titular de outra empresa; c) contrate no máximo um empregado; d) exerça uma das atividades econômicas previstas no Anexo XIII, da Resolução do Comitê Gestor do Simples Nacional de $n^{\circ}$ 94/2011, o qual relaciona todas as atividades permitidas ao MEI.

Para se formalizar como MEI, é importante observar as seguintes ressalvas previstas na Lei:

a) Pessoa que recebe o Seguro Desemprego: Pode ser formalizada, mas poderá ter a suspensão do benefício. Em caso de suspensão, deverá recorrer nos postos de atendimento do Ministério do Trabalho; 
b) Pessoa que trabalha registrada no regime CLT: Pode ser formalizada, mas, em caso de demissão sem justa causa, não terá direito ao Seguro Desemprego;

c) Pessoa que recebe Auxílio Doença: Pode ser formalizada, mas perde o benefício a partir do mês da formalização;

d) Pessoa que recebe aposentadoria por invalidez;

e) Pessoas que recebem Bolsa Família: $O$ registro no MEI não causa o cancelamento do programa Bolsa Família, a não ser que haja aumento na renda familiar acima do limite do programa. Mesmo assim, o cancelamento do benefício não é imediato, só será efetuado no ano de atualização cadastral (CONTÁBIL SIMPLES, 2019).

O cidadão que se formalizar como MEI se beneficiará das seguintes vantagens:

a) Aposentadoria por idade: mulher aos 60 anos e homem aos 65, observado a carência, que é tempo mínimo de contribuição de 180 meses, a contar do primeiro pagamento em dia; especificamente para esse benefício, mesmo que o segurado pare de contribuir por bastante tempo, as contribuições para aposentadoria nunca se perdem, sempre serão consideradas;

b) Auxílio doença e Aposentadoria por invalidez: são necessários 12 meses de contribuição, a contar do primeiro pagamento em dia. É importante saber que, em relação ao benefício auxílio-doença e aposentadoria por invalidez, nos casos de acidente de qualquer natureza ou se houver acometimento de alguma das doenças especificadas em lei, independe de carência a concessão desses dois benefícios.

c) Salário-maternidade: são necessários 10 meses de contribuição, a contar do primeiro pagamento em dia (PORTAL DO EMPREENDEDOR, 2019).

A nova legislação trouxe benefícios para os microempreendedores como para a economia brasileira de um modo geral, tais como:

Os trabalhadores contam com o recolhimento do INSS, tem acesso ao crédito, podem participar de licitações, com possibilidade de crescimento, podendo inclusive no futuro serem sócios de microempresa. Trata-se de uma grande oportunidade para prestadores de serviço autônomos como eletricistas e bombeiros hidráulicos, além de vendedores 
ambulantes [...] regularizarem sua situação, podendo negociar suas mercadorias com o acobertamento de notas fiscais, o que lhes abre um grande espaço para comprar de empresas com as quais antes ele não conseguia por falta de documentação. Além disso, eles agora não precisam temer a ação policial [...], nem se queixar da carga tributária, bastante reduzida pela nova lei (SANTOS e FREITAS, 2012, p.7)

Segundo Schwingel e Rizza (2013), após a formalização, o MEI tem acesso ao crédito, máquinas de cartão de crédito e podem concorrer em licitações com o objetivo de ser contratado pelo serviço público, sendo uma "inclusão produtiva".

Pacobahyba (2011) explana que, em plena consonância com as recentes transformações da sociedade proporcionadas pela tecnologia, o microempreendedor individual conta com uma importante ferramenta na rede mundial de computadores, a fim de se esclarecer sobre os benefícios que contarão com a formalização.

Ressaltasse, ainda, que a idade mínima para poder se formalizar como MEI é de 18 anos; porém, poderão registrar-se como MEI as pessoas maiores de 16 anos e menores de 18 anos legalmente emancipadas. Nesse último caso, é obrigatório, ao se inscrever no Portal do Empreendedor, o preenchimento eletrônico da Declaração de Capacidade, com o seguinte texto: "Declaro, sob as penas da Lei, ser legalmente emancipado" (GLOBAL ADM, 2019).

\subsection{A ROTINA NO CENTRO SOCIOEDUCATIVO DURANTE O CURSO MEI}

O Centro de Atendimento Socioeducativo de Cáceres-MT funciona num antigo prédio da Delegacia de Roubo e Furtos. Atualmente, o gerente responsável pela unidade coordena uma equipe composta de servidores estaduais, entre eles, o psicólogo, o assistente social, educador físico, técnicos em enfermagem, assistentes administrativos e agentes socioeducativos que trabalham em plantões de 24 por 72 horas.

O Projeto teve início no mês de agosto com a apresentação do curso MEI, ministrado aos 12 adolescentes que cumpriam medidas socioeducativas. As aulas ocorriam uma vez por semana e duravam entre 2 e 3 horas, conforme a situação em que se encontravam com relação às normas de condutas estabelecidas pela gerência.

Por questão de segurança, os 12 participantes foram divididos em 4 grupos de estudos com 3 adolescentes cada. As aulas por grupos duravam em torno de 40 minutos no intervalo entre as 14:00 e 16:30hs. A maioria dos adolescentes 
cumpriam as medidas socioeducativas por terem se envolvido em tráfico de drogas, tentativa de homicídio, homicídio e estupros. Entre eles, havia um que pertencia ao Primeiro Comando da Capital (PCC).

No início do projeto havia uma preocupação constante com a segurança do professor devido à mudança da rotina que ocorria durante as aulas. Percebia-se uma preocupação constante dos agentes socioeducativos devido aos casos recentes de professores feitos reféns pelos adolescentes para fugir do Centro Socioeducativo. Nas primeiras aulas, alguns adolescentes compareciam com as algemas nos pés.

Foram várias as situações atípicas ocorridas durante o período em que foi ministrado o curso MEI que prejudicaram o andamento e o desempenho dos participantes (12), tais como: problemas de saúde dos mais diversos tipos; brigas entre eles que eram punidos com a separação dos grupos formados; e, ainda, quando não estavam animados para assistirem as aulas.

O grau de escolaridade da maioria dos adolescentes participantes era ensino fundamental incompleto (67\%), sendo os demais com o ensino médio incompleto. Durante as aulas, percebia-se que a maioria se dispersava facilmente quando o assunto era explicado.

Após contatos com todos os quatro grupos, houve a necessidade de se ajustar aos participantes do projeto, como por exemplo, a mudança a linguagem técnica do assunto para uma linguagem acessível, principalmente trazendo vários exemplos do dia-a-dia que eles iriam encontrar ao ganharem a liberdade.

Além disso, optou-se em selecionar aqueles que realmente demonstravam interesse em participar efetivamente do projeto, pois até aquele momento não era possível dar continuidade ao cronograma estabelecido para o curso MEI, devido aos problemas comentados anteriormente.

Assim sendo, foram selecionados quatro adolescentes que em todos os encontros presenciais demonstraram interesse no assunto e, principalmente, tinham bom comportamento em relação aos demais. Após a seleção realizada entre os adolescentes participantes, foi possível seguir o cronograma do curso MEI, que encerrou com um mês depois do previsto.

A partir daí, foram adotadas algumas estratégias de ensino ajustadas, conforme a necessidade de cada participante. Inicialmente, foi confeccionada pelo coordenador e professor do projeto de extensão uma apostila sobre MEI com base na Lei Complementar 123 de 14 de dezembro de 2006 e na Lei Complementar $n^{\circ} 128$ de 19 de dezembro de 2008, com a transformação da linguagem 
técnica do conteúdo do curso para uma linguagem acessível conforme o grau de escolaridade dos adolescentes.

As aulas foram realizadas no próprio Centro Socioeducativo, numa sala pequena, adaptada conforme evidenciada na imagem 3 , com o grupo dos adolescentes selecionados, sendo ministrado uma parte do conteúdo presencial e o restante a distância.

Para as aulas não presenciais, trabalharam-se materiais teóricos e exercícios sobre o conteúdo ministrado nas aulas anteriores. Após cada dois encontros presenciais, aplicaram-se avaliações abordando-se o tema do curso. A carga horária não presencial era cumprida no próprio Centro Socioeducativo, ou seja, na própria cela onde os adolescentes permaneciam.

As avaliações foram compostas de questões múltiplas objetivas, com a linguagem adaptada ao nível de aprendizado e entendimento dos adolescentes. Antes da primeira avaliação, realizou-se um pré-teste com questões objetivas e subjetivas para verificar qual foi a melhor opção para aplicação das avaliações.

No período do curso, realizaram-se 5 avaliações, sendo a última uma apresentação em forma de uma mesa redonda, com a apresentação para os familiares e alguns convidados.

Nas avaliações seguintes, não houve dificuldades de entendimento por parte deles, tendo em vista que o professor explicava cada questão da avaliação. O resultado geral obtido no curso está evidenciado no gráfico 1.

GRÁFIco1-Desempenho nas Avaliações

Desempenho Individual

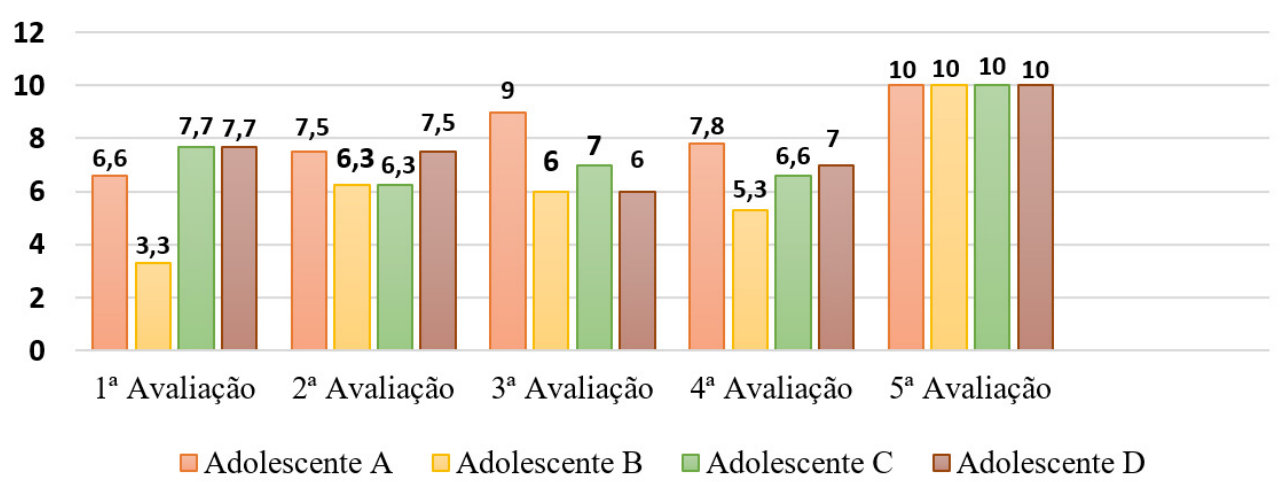

Fonte: Relatório PARCIAL do PROJETO de EXTENSÃo (2018)

A $5^{\mathrm{a}}$ e última avaliação foi obtida por meio de apresentação de uma mesa redonda composta pelos quatros adolescentes para os familiares e demais 
convidados no último dia de aula do curso. Antes da apresentação, foi realizado treinamento da mesa redonda na qual realizou-se um bate-papo, sendo um dos adolescentes apresentador do programa Contabilizando a Liberdade" e os outros três como convidados. Nesse evento, destacou-se a participação efetiva das duas graduandas do curso de Ciências Contábeis da $6^{\text {a }}$ Fase que orientaram os adolescentes quanto ao comportamento e a forma de se apresentar perante o público.

Convém aqui comentar a experiência compartilhada pelas duas graduandas quanto aos contatos com os adolescentes. De início, as duas graduandas foram orientadas em não saber quais os crimes cometidos pelos adolescentes, para não criar um clima de apreensão e medo. Porém, no decorrer do curso, algum agente passou as informações sobre o que fizeram os adolescentes para estarem cumprindo medidas socioeducativas. Depois de uma boa conversa, essa situação foi resolvida. Após a apresentação, foi realizada a entrega do Certificado de Conclusão do Curso pelos familiares dos adolescentes que estavam presentes ao evento. Conforme evidenciado na Imagem 1.

IMACEM 1 - Entrega do Certificado
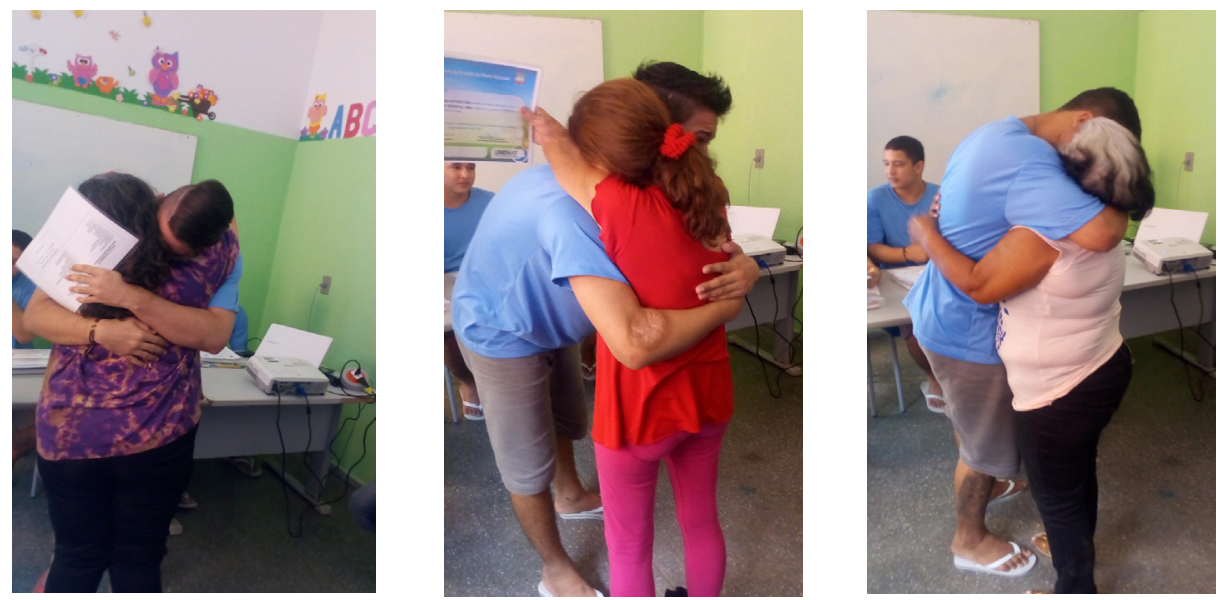

Fonte: Relatório PARCial do Projeto de EXtensão (2018)

Ao final de quase dois meses de estudos, todos os adolescentes concluíram com aproveitamento o curso Microempreendedor Individual (MEI) e receberam o Certificado concedido pela UNEMAT. 


\section{CONCLUSÃO}

Percebeu-se durante o curso que as atividades realizadas contribuíram positivamente para a valorização da dignidade, da cidadania perdida e, principalmente, da autoestima de cada adolescente participante do projeto. Observou-se, ainda, a mudança dos comportamentos dos adolescentes que possibilitou a construção de novas relações interpessoais, facilitando um melhor relacionamento entre os participantes, entre os próprios adolescentes com os agentes socioeducativos.

Durante o evento de encerramento do curso, que contou com a presença de vários convidados, principalmente os familiares dos adolescentes, percebeu-se, pelos testemunhos dos pais e avós, uma melhora considerável na relação afetiva entre eles.

Vale ressaltar, ainda, o despertar do interesse dos adolescentes pelos estudos e principalmente por temas contábeis, fato observado pelos comentários feitos pelos adolescentes durante os encontros presenciais.

Além disso, os adolescentes foram incentivados a romper barreiras relacionadas à motivação e auto expressão e também estimulados a desenvolver a potencialidade de suas funções cognitivas. Para o coordenador e professor, o projeto criou oportunidades de reflexão sobre a realidade dos adolescentes que se encontram cumprindo medidas socioeducativas e também sobre a possibilidade de contribuir de forma efetiva para a ressocialização deles à sociedade, proporcionando-lhes crescimento profissional, pessoal e espiritual.

O Curso de Microempreendedor Individual (MEI) aqui apresentado constituiu uma excelente oportunidade de reforçar o relacionamento entre a UNEMAT e a sociedade, em especial os adolescentes que cumprem medidas socioeducativas, na medida em que este se apresentou com uma via de mão dupla da qual a comunidade acadêmica teve a oportunidade de aplicar seus conhecimentos em benefício da sociedade. No encerramento do curso e no retorno à Universidade, as graduandas envolvidas testemunharam sobre as experiências obtidas na área pessoal e profissional, possibilitando a geração de novos saberes. 


\section{REFERÊNCIAS}

BRASIL. Constituição Federal de 05 de outubro de 1988. Constituição da República Federativa do Brasil. Brasília: Senado Federal, 1988. Disponível em: <http://www.planalto.gov.br/ccivil_03/constituicao/constituicaocompilado.htm>. Acesso em: 29 jan. 2019.

. Lei no 8.069 de 13 de julho de 1990. Dispõe sobre o Estatuto da Criança e do Adolescente e dá outras providências. Brasília: Presidência da República do Brasil, 1990. Disponível em: <http://www.planalto.gov.br/ccivil_03/LEIS/L8069.htm>. Acesso em: 21 dez. 2018.

. Lei Complementar no 123 de 14 de dezembro de 2006. Institui o Estatuto Nacional da Microempresa e da Empresa de Pequeno Porte. Brasília: Presidência da República do Brasil, 2006. Disponível em: <http://www.planalto.gov.br/ccivil_03/LEIS/ LCP/Lcp123.htm>. Acesso em: 21 dez. 2018.

. Lei Complementar no 128 de 19 de dezembro de 2008. Altera a Lei Complementar no 123 de 14 de dezembro de 2006.. Brasília: Presidência da República do Brasil, 2006. Disponível em: <http://www.planalto.gov.br/ccivil_03/LEIS/LCP/Lcp123.htm>. Acesso em: 21 dez. 2018.

CONHEÇA AS VANTAGENS E OBRIGAÇÕES DE SER UM MEI. Disponível em: <http://www.portaldoempreendedor.gov.br/temas/quero-ser/formalize-se/quais-sao-seus-direitos-e-obrigacoes>. Acesso em: 30 jan. 2019.

FORPROEX - FÓRUM DE PRÓ-REITORES DE EXTENSÃO DAS UNIVERSIDADES PÚBLICAS BRASILEIRAS. Plano Nacional de Extensão Universitária. Ilhéus: Editus, 2001. (Extensão Universitária, v.1).

IDADE MÍNIMA PARA SE FORMALIZAR COMO MEI. Disponível em: <https://globaldm.com.br/duvidas-frequentes-sobre-mei>. Aceddo em; 30 jan. 2019.

NOGUEIRA, M. D. P. Políticas de Extensão Universitária Brasileira. Belo Horizonte: Editora UFMG, 2005.

OLIVEIRA, O. V.; FORTE, S. H. A. C. Microempreendedor individual: fatores da informalidade. CONEXXIO, v. 4, n. Esp., p. 27-42, 2014. ISSN 2236-8760.Disponível em: $<$ https://repositorio.unp.br/index.php/connexio/article/viewFile/800/505> Acesso em: 07 nov. 2018.

PACOBAHYBA, F. M. O. M. C. O Microempreendedor Individual como Expressão da Extrafiscalidade no Direito Tributário Nacional. 2011. 105f. Dissertação (Mestrado em Direito Constitucional)-Universidade de Fortaleza. Fortaleza: UNIFOR, 2011.

LOPES, Juliana Dias; CAMPOS, Flávia Rezende. Processo de formalização do Microempreendedor Individual Goiano. Conjuntura Econômica. Goiana, n. 18, p 6370, out. 2011. Disponível em: <http://www.seplan.go.gov.br/sepin/pub/conj/conj18/ artigo06.pdf $>$. Acesso em: 21 nov. 2018. 
SANTOS, J. D.; FREITAS, R. C. O Microempreendedorismo Individual: um passo positivo para a economia brasileira. 2012. Disponível em: $<$ https://www.passeidireto. com/arquivo/5695401/microempreendedor individual/1> Acesso em: 09 out. 2018.

SISTEMA NACIONAL DE ATENDIMENTO SOCIOEDUCATIVO (SINASE). Levantamento Anual. Brasília, 2016. Disponível em: <http://www.mdh.gov.br/ todas-as-noticias $/ 2018 / \mathrm{marco} / \mathrm{mdh}$-divulga-dados-sobre-adolescentes-em-unidades-de-internacao-e-semiliberdade>. Acesso em: 29 jan. 2019.

SITUAÇÕES QUE PERMITEM A FORMALIZAÇÃO COMO MEI, COM RESSALVAS. Disponível em: $<$ https://contabilsimples.com/> Acesso em: 30 jan. 2019.

SCHWINGEL, I; RIZZA, G. Políticas públicas para formalização das empresas: lei geral das micro e pequenas empresas e iniciativas para a desburocratização. Governo Federal, Ministério do Trabalho e Emprego, v. 54, p. 48, 2013. Disponível em: <http:// repositorio.ipea.gov.br/bitstream/11058/3846/1/bmt54_politicaemfoco_politicpublica.pdf > Acesso em: 17 out. 2018.

UNIVERSIDADE ESTADUAL DO MATO GROSSO. Pro-reitoria de Extensão e Cultura. Cáceres, 2018. Disponível em: <http://portal.unemat.br/index. php?pg=site\&i=proec\&m=projetos-e-programas $>$. Acesso: 29 jan. 2019. 